\title{
PENGELOLAAN CEDERA SPRAIN TINGKAT II PADA PERGELANGAN KAKI
}

\author{
Oleh: Bambang Priyonoadi \\ Dosen Jurusan Pendidikan Kesehatan dan Rekreasi FIK UNY
}

Abstrak

Pada waktu berolahraga, sering terjadi cedera pada daerah sendi pergelangan kaki. Sendi pergelangan kaki mudah sekali mengalami cedera karena kurang mampu melawan kekuatan medial, lateral, tekanan, dan rotasi.

Cedera yang mengenai ligamen disebut sprain. Pada sendi pergelangan kaki terdapat banyak ligamen, dan ligamentum tersebut bisa terkena sprain dengan berbagai tingkatan di antaranya tingkat I (terdapat sedikit hematoma dalam ligamen dan hanya beberapa serabut yang putus), tingkat II (lebih banyak serabut otot dari ligamentum yang putus, tetapi lebih separo serabut ligamentum masih utuh), tingkat III (seluruh ligamentum putus sehingga kedua ujungnya terpisah). Cedera sprain tingkat II pada ligamentum pergelangan kaki kalau tidak segera dikelola dapat berakibat menuju cedera yang lebih berat atau ke tingkat III.

Pengelolaan cedera sprain tingkat II pada pergelangan kaki terdiri atas lima fase, yaitu fase I bertujuan untuk mengontrol pengeluaran darah, pembengkakan, rasa sakit, dan kejang. Diperkirakan lama waktu 2-3 hari; fase II pemeliharaan lanjutan, yaitu dengan semua perlakuan dan segera dilanjutkan dengan latihan; fase III bertujuan untuk memulihkan $50 \%$

Vol. I, No. 2, Oktober 2005: 142-153. 
bebas dari sakit pada waktu bergerak dan memulihkan kekuatan; fase IV bertujuan untuk memulihkan $90 \%$ luas gerak sendi (range of motion/ROM), power, daya tahan, kecepatan, dan kelincahan. Lama waktu yang dibutuhkan 1 minggu; dan fase $\mathrm{V}$ bertujuan penderita bebas dari gejala dan mempunyai ROM yang baik. Keberhasilan penyembuhan cedera bergantung pada tingkat kedisiplinan, ketekunan, dan kemauan untuk menjalankan urutan perawatan. Kriteria dari sembuh total pada cedera sprain tingkat II pergelangan kaki adalah bebas dari kepincangan dalam gerak dan tidak ada pembengkakan, ROM pada pergelangan kaki berfungsi baik dan kekuatan kembali normal, penderita dapat berlari, melompat dan dapat membuat perbaikan gerak yang baik seperti sebelum cedera.

Kata kunci: sprain, pergelangan kaki.

Setiap melakukan aktivitas fisik khususnya berolahraga selalu dihadapkan kemungkinan cedera dan cedera ini akan berdampak pada gangguan aktivitas fisik, psikis, dan prestasi. Salah satu anggota tubuh yang paling sering mengalami cedera adalah pada bagian sendi pergelangan kaki. Cedera ini dapat terjadi karena terkilir secara mendadak ke arah lateral atau medial yang berakibat robeknya serabut ligamentum pada sendi pergelangan kaki (Arnheim, 1985: 473, Peterson, 1990: 341, Brukner, P. dan Khan, K., 1993: 439). Di tiap-tiap persendian terdapat serabut-serabut otot yang menghubungkan tulang satu dengan tulang yang lainnya. Serabut otot ini disebut ligamentum. Cedera yang mengenai pada daerah ligamentum ini sering disebut sprain, sedangkan cedera yang mengenai pada unit musculo tendinous disebut sprain. 


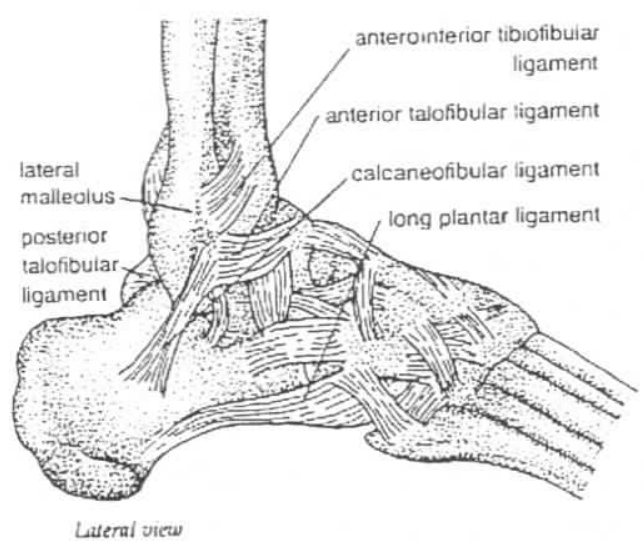

Gambar 1. Anatomi Persendian Pergelangan Kaki Dilihat dari Sisi Lateral (Brukner, P., dan Khan, K., Clinical Sports Medicine., 1993: 439)

Gambar 2. Anatomi Persendian Pergelangan Kaki Dilihat dari Sisi Medial (Brukner, P., dan Khan, K., Clinical Sports Medicine., 1993: 439)

Walaupun sendi pergelangan kaki merupakan persendian yang tidak begitu besar dalam tubuh, kenyataannya pada sendi pergelangan kaki mudah sekali terserang cedera traumatik. Persendian ini mudah cedera karena kurang mampu melawan kekuatan medial, lateral, tekanan, dan rotasi karena lemahnya otot atau lapisan lemak. Kesemuanya ini terjadi karena adanya perintah gerak untuk mengubah secara cepat, sedangkan kondisi permukaan tanah tidak memungkinkan. Kontak langsung dengan kaki pemain lain juga dapat mengganggu keseimbangan dalam melompat atau mendarat, contoh konkret sewaktu berolahraga adalah pada permainan basket, voli, bulutangkis, tenis, dan sepakbola (Brukner, P. dan Khan, K., 1993: 442).

Cedera pada serabut otot ligamentum (sprain) menurut Sadoso (t.t.: 8) dan Brukner \& Khan (1993: 12) terdiri atas beberapa tingkatan, yaitu:

1. Sprain tingkat I. Pada cedera ini terdapat sedikit hematoma dalam ligamentum dan hanya beberapa serabut yang putus.

2. Sprain tingkat II. Pada cedera ini lebih banyak serabut otot dari ligamentum yang putus, tetapi lebih separoh serabut ligamentum masih utuh.

3. Sprain tingkat III. Pada cedera ini seluruh ligamentum putus sehingga kedua ujungnya terpisah. 


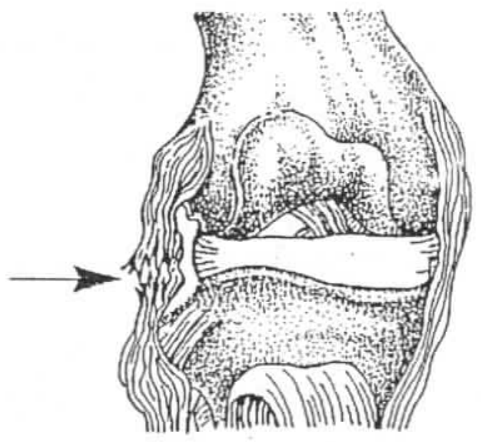

Gambar 3. Sprain Tingkat I

Gambar 4. Sprain Tingkat II

(Dikutip dari Sadoso., Cedera Olahraga di Arena., t.t.: 8; dan Brukner \& Khan, Clinical Sports Medicine., 1993: 12)

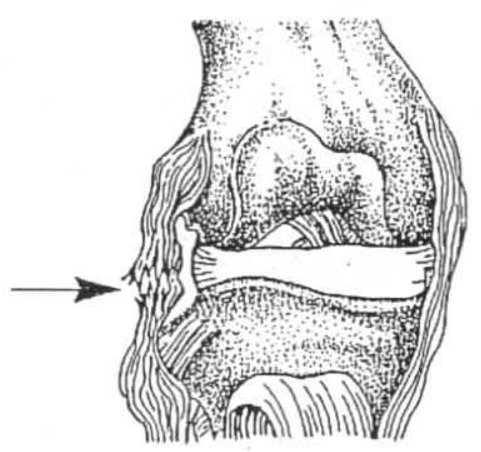

Gambar 5. Sprain Tingkat III

(Dikutip dari Sadoso., Cedera Olahraga di Arena., t.t.: 8; dan Brukner \& Khan, Clinical Sports Medicine., 1993: 12)

Pergelangan kaki harus dijaga betul agar terhindar dari kemungkinan cedera, dan andaikata cedera tetap terjadi secepat mungkin harus diatasi. Dengan demikian, atlet, pelatih, pembina, guru olahraga, maupun pemerhati olahraga sangat perlu memperoleh beberapa pengetahuan dan keterampilan upaya perawatan cedera pada sendi pergelangan kaki agar dapat melakukan perawatan secara tepat dan cepat.

Pengelolaan Cedera Sprain Tingkat II pada Pergelangan Kaki (Bambang Priyonoadi) 
Tulisan ini hanya akan membahas cedera sprain tingkat II pada sendi pergelangan kaki, khususnya tentang mekanisme terjadinya cedera sendi pergelangan kaki, upaya penanganan dini dan pengelolaan cedera tersebut.

\section{MEKANISME CEDERA}

Terkilir pada pergelangan kaki biasanya disebabkan oleh gerakan ke sisi luar/samping (lateral) atau ke sisi dalam/tengah (medial) dari pergelangan kaki yang terjadi secara mendadak. Terkilir secara inversi yaitu kaki berbelok dan atau membengkok ke dalam dan terbalik. Tipe ini merupakan cedera yang paling umum terjadi pada pergelangan kaki (Arnheim, 1985: 473; Peterson dan Renstrom, 1990: 345-346). Hal ini disebabkan oleh banyaknya tulang penstabil pada sisi sebelah samping yang mengakibatkan tekanan pada kaki menjadi terbalik. Jika kekuatan tersebut cukup besar, pembengkokan dari pergelangan kaki terjadi sampai medial malleolus kehilangan stabilitasnya dan menciptakan titik tumpu untuk lebih membalikkan pergelangan kaki (Arnheim, 1985: 473).

Ketika serabut otot ligamentum untuk eversi tidak cukup kuat untuk menahan atau melawan kekuatan inversi, maka serabut ligamentum sisi sebelah samping menjadi tertekan atau robek.
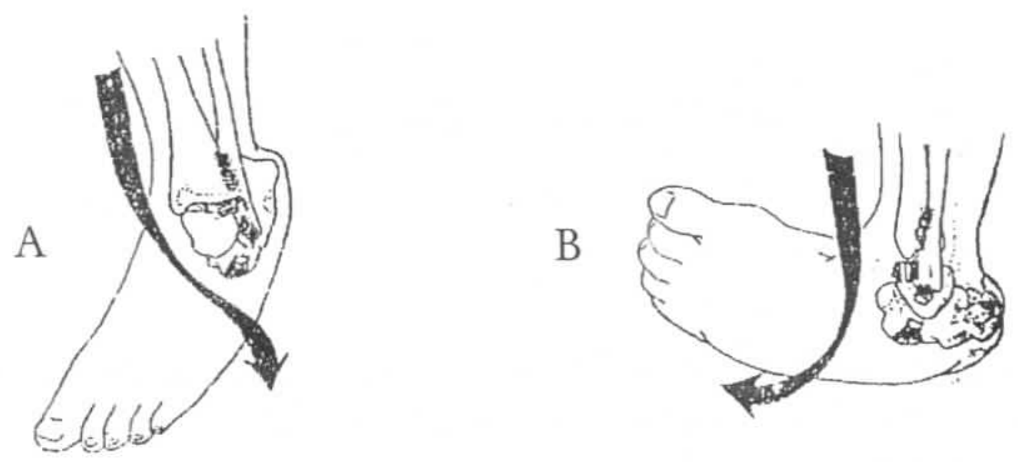

Gambar 6. Mekanisme Cedera Sprain Pergelangan Kaki dengan Pola Inversi (Arnheim, Modern Principles of Atbletic Training., 1985: 473; Peterson dan Renstrom, Sports Injuries: Their Prevention and Treatment., 1990: 344)

METHRORA Vol. I, No. 2, Oktober 2005: 142-153. 
Biasanya terkilir pada kaki bagian samping meliputi satu atau dua robekan pada serabut ligamentum. Jika satu ligamentum robek, biasanya termasuk juga ligamentum calcaneal fibular akan robek pula (lihat gambar 7).

Tekanan yang kuat pada tumit menekan kaki menjadi inversi, membuatnya lebih mungkin untuk terjadi sprain pada sisi sebelah luar/ samping. Kebalikannya, kaki yang pronasi, kelebihan gerakan atau adanya tekanan dari telapak kaki sisi sebelah dalam/tengah secara longitudinal lebih memungkinkan untuk terjadi eversi sebagai salah satu pola sprain pada pergelangan kaki (Arnheim, 1985: 473).

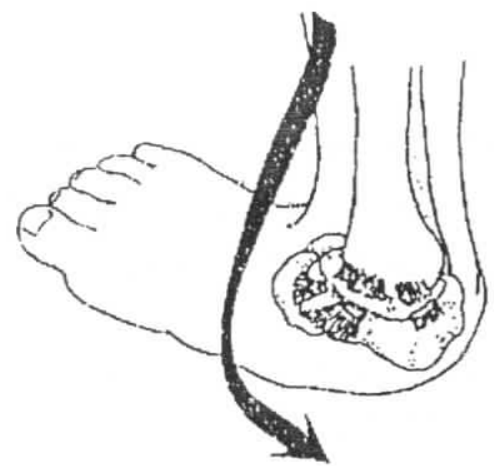

Gambar 7. Mekanisme Cedera Pada Pergelangan Kaki dengan Pola Eversi

(Arnheim, Modern Principles of Atbletic Training., 1985: 473; Peterson dan Renstrom, Sports Injuries: Their Prevention and Treatment ., 1990: 348)

Cedera sprain pada pergelangan kaki dengan pola eversi lebih jarang terjadi daripada cedera sprain dengan pola inversi. Mekanisme yang biasa terjadi adalah olahragawan yang tiba-tiba menapakkan kakinya pada lubang di lapangan olahraga menyebabkan kaki tergerak dengan paksa dan menanamkan kaki pada gerakan yang eksternal. Dengan mekanisme ini ligamentum anterior tibiofibular, ligamentum interosseous, dan ligamentum deltoid menjadi robek. Perobekan pada ligamentum tersebut menyebabkan talus bergerak secara lateral, terutama mengakibatkan degenerasi pada persendian, dan juga berakibat adanya ruangan abnormal antara medial malleolus dan talus (Arnheim, 1985: 473; Peterson dan Renstrom, 1990: 342 343). 


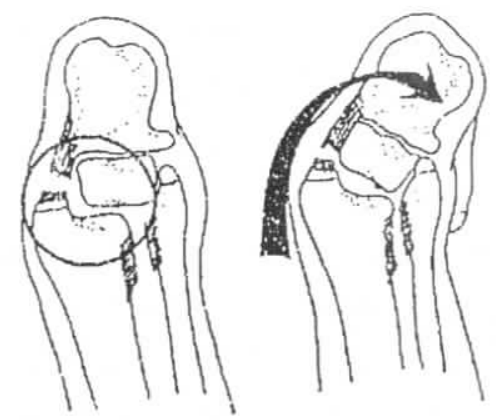

Gambar 8. Gambaran Ruang Abnormal antara Medial Malleolus dan Talus pada Cedera Sprain Pergelangan Kaki dengan Pola Eversi (Arnheim, Modern Principles of Atbletic Training., 1985: 473)

Kekuatan inversi secara tiba-tiba dapat menyebabkan berbagai intensitas seperti menyebabkan patah pada kaki bagian bawah. Perputaran yang tidak diharapkan pada ligamentum lateral dapat menyebabkan bagian tulang menjadi avulsi dari malleolus. Satu situasi yang khusus adalah ketika lateral malleolus teravulsi oleh tulang calcaneofibular, dan talus melawan medial malleolus untuk menghasilkan patah yang kedua kalinya. Kejadian ini sering disebut bimalleolar fracture.
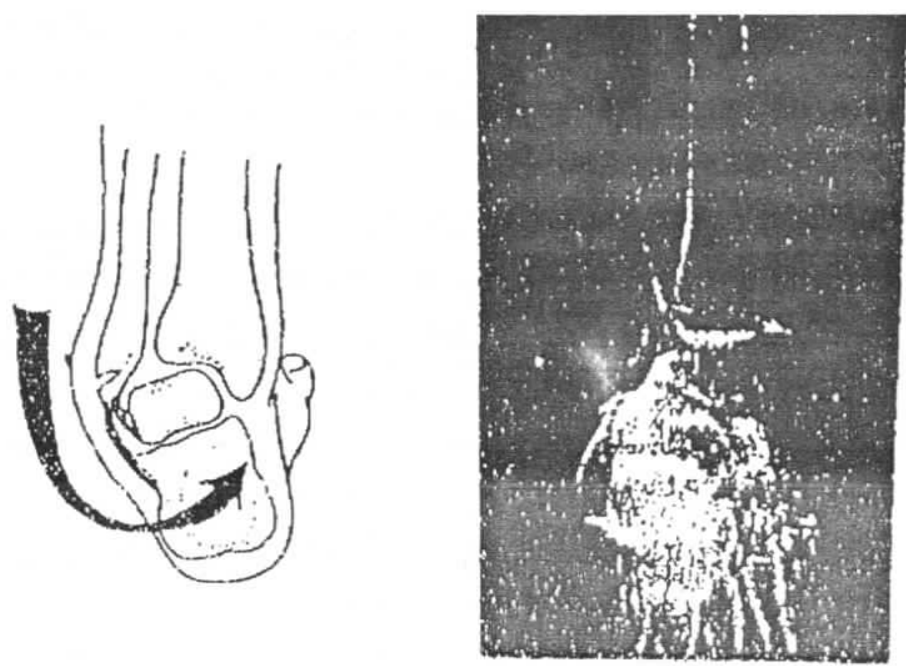

Gambar 9. Cedera Sprain pada Pergelangan Kaki Berakibat Patah Tulang Dikarenakan Avulsi (Arnheim, Modern Principles of Atbletic Training., 1985: 474)

MEDUHERA Vol. I, No. 2, Oktober 2005: 142-153. 


\section{GEJALA DAN TANDA-TANDA}

Setelah cedera, penderita mengeluh sakit tersiksa yang berlebihan pada aspek anterolateral pada sendi pergelangan kaki. Perabaan di atas sakit keras tersebut hanya di bawah malleolus lateral.

Dengan cepat penyebaran terjadi di tempat bengkak yang berlebihan pada daerah pergelangan kaki sisi lateral dan anterior, persamaan tes ditunjukkan adanya ketidakseimbangan. Sinar X diindikasikan tidak patah tulang. Sprain ini akan diklasifikasikan menjadi tingkat II.

\section{PENGELOLAAN CEDERA SPRAIN TINGKAT II PADA PERGELANGAN KAKI}

\section{Fase I}

\section{Tujuan:}

Untuk mengontrol pengeluaran darah, pembengkakan, rasa sakit, dan kejang. Diperkirakan lama waktu 2-3 hari.

\section{Perawatan:}

1. Segera diberi kompres es selama 20 menit secara selang-seling 6-8 kali sehari.

2. Gunakan pembungkus elastis selama jam-jam perawatan dan dengan selalu mengangkat kaki.

3. Kaki di angkat di atas bantal selama tidur.

4. Tongkat ketiak digunakan untuk menghindari penahanan beban sedikitnya selama 3-4 hari atau sampai penderita dapat berjalan tanpa keluhan/ pincang.

5. Buka tali ikatan pembungkus elastis, ini diperlukan untuk mengontrol pengeluaran darah selama 2-3 hari.

\section{Latiban Rebabilitasi:}

1. Memegang jari kaki dan membentangkan jika tidak ditimbulkan sakit selama 10-15 kali setiap jam dijaga, dimulai pada hari kedua setelah cedera.

2. Latihan pemeliharaan seluruh tubuh dengan dituntun 3 kali seminggu, lama kelamaan tidak memberatkan cedera. 


\section{Fase II}

\section{Tujuan:}

Pemeliharaan lanjutan, yaitu dengan semua perlakuan dan segera dilanjutkan dengan latihan. Beri kompres es 5-15 menit, dapat juga dengan masase es selama 7 menit dengan 2-3 kali sehari, atau oleskan air dingin $\left(60^{\circ}-90^{\circ} \mathrm{F}\right)$, juga bisa dengan mandi kontras/mandi arus selama 20 menit atau dengan cara masase bagian atas dan bawah tempat cedera selama 5 menit.

\section{Latiban Rebabilitsi:}

1. Berjalan dengan tongkat ketiak dilanjutkan dengan menyentuh jari jika penderita tidak mampu berjalan tanpa pincang.

2. Lakukan dengan memegang dan membentangkan jari kaki selama 10-15 kali setiap jam di jaga. Memberi contoh latihan PNF sendi pergelangan kaki 3-4 kali sehari.

3. Latihan pemulihan seluruh tubuh dengan dituntun 3 kali seminggu, bisa dipastikan bahwa lama kelamaan penderita tidak semakin berat cederanya.

\section{Fase III}

\section{Tujuan:}

Untuk memulihkan $50 \%$ bebas dari sakit pada waktu bergerak dan memulihkan kekuatan.

\section{Perawatan:}

Semua perlakuan dilanjutkan dengan latihan.

Beri kantong es (ice pack) selama 5-15 menit atau dengan masase es selama 7 menit dan dilakukan 2-3 kali sehari, atau dengan oleskan air dingin $90^{\circ}-100^{\circ} \mathrm{F}$ selama 10 sampai 15 menit, atau dengan mandi contrast selama 20 menit, juga bisa dengan masase bagian atas dan bawah pada bagian yang cedera selama 5 menit, atau bisa dengan ultrasound 0,5 watt $/ \mathrm{cm}$ selama 5 menit.

Meditiera Vol. I, No. 2, Oktober 2005: 142-153. 


\section{Latiban Rebabilitasi:}

1. Menghindari latihan yang menimbulkan rasa sakit atau pembengkakan.

2. Memutar pergelangan kaki selama 10-15 kali selama 2-3 kali sehari.

3. Tendo achilles diregangkan di lantai selama 30 detik pada setiap posisi kaki (jari-jari ke dalam, jari-jari ke luar, lurus ke depan, lakukan selama 3-4 kali sehari).

4. Mengangkat jari kaki selama 10 kali, 1-3 set, dilakukan selama 3-4 kali sehari.

5. Bentuk latihan menggunakan handuk atau tube pemijat/pakaian resistensi dengan dikerjakan selama 3-4 kali sehari.

6. Membantu berat badan/beban tubuh antara cedera dan tidak cedera pada pergelangan kaki, gerakan ini dapat dikerjakan selama 20 menit sampai terjadi bebas dari sakit. Kegiatan tersebut dikerjakan selama 2-3 kali sehari.

7. Mengerjakan stretching dengan cara proprioceptive neurofasilitator (PNF) pada pergelangan kaki dengan dibantu partner/orang lain selama 2-3 kali sehari.

8. Dilanjutkan dengan gerak maju lurus ke depan berjalan dengan langkah pendek, jika tidak dapat dilakukan tanpa pincang.

Latihan pemeliharaan pada fase III ini dilaksanakan dengan frekuensi 3 kali seminggu, diharapkan lama kelamaan penderita merasakan cedera yang dialami semakin berkurang rasa sakitnya.

\section{Fase IV}

\section{Tujuan:}

Untuk memulihkan $90 \%$ luas gerak sendi (range of motion/ROM), power, daya tahan, kecepatan dan kelincahan. Lama waktu yang dibutuhkan 1 minggu.

\section{Perawatan:}

Semua perlakuan segera dilanjutkan dengan latihan.

Pemberian kantong es selama 5 menit atau dengan masase es selama 7 menit satu kali sehari, atau dengan oleskan air (whirepool) $100^{\circ}-120^{\circ} \mathrm{F}$, atau dengan mandi contrast (contrast bath) selama 20 menit, atau dapat juga dengan ultrasound $0,5 \mathrm{watt} / \mathrm{cm}$ selama 5 menit. 


\section{Latiban Rebabilitasi:}

1. Peregangan tendo achilles menggunakan papan miring selama 30 detik sampai posisi kaki 2-3 kali sehari.

2. Mengangkat jari kaki dengan menggunakan papan miring dan resistensi selama 10 repetisi, 1-3 set dikerjakan 2-3 kali sehari.

3. Tujuan resistensi pada pergelangan kaki adalah untuk memperkuat otot anterior, lateral, dan medial. Dimulai dengan 2 lebius dan dinaikkan sampai 10 lebius selama 1-3 set dikerjakan 2-3 kali sehari.

4. Gunakan papan miring untuk propriosepti pergelangan kaki dari 1 menit sampai sambil dituntun dan dinaikkan selama 5 menit dikerjakan selama 3 kali sehari.

5. Jalan jogging rutin, lama kelamaan akan bebas dari gejala, dapat dimulai sebagai alternatif jalan-joging-lari-jalan 25 yard lurus ke depan, jogging lurus ke depan 25 yard; dinai'kan untuk jalan 25 yard dalam leter $\mathrm{S}$ atau 5 macam-8 S; dinaikkan untuk 8 macam berlari memungkinkan makin cepat; ketika penderita dapat untuk lari 10 macam-8S atau membentuk Z, memungkinkan makin cepat dan dapat lompat ke atas di udara pada kaki cedera 10 kali tanpa pincang.

Fase 5 dapat dimulai.

\section{Fase V}

Penderita bebas dari gejala dan mempunyai ROM yang baik.

\section{Latiban Rebabilitasi:}

Dengan perlindungan pada pergelangan kaki oleh pembalut atau dengan membelit dapat mengembalikan penguatan latihan dan melatih ROM agar dapat digunakan lagi sehari-hari.

\section{KRITERI UNTUK SEMBUH TOTAL}

1. Pergelangan kaki bebas dari kepincangan dalam gerak dan tidak ada pembengkakan.

2. ROM pada pergelangan kaki berfungsi baik dan telah mendapatkan kekuatannya kembali seperti sebelum cedera. 
3. Penderita dapat berlari, melompat dan dapat membuat perbaikan gerak yang baik seperti sebelum cedera.

\section{KESIMPULAN}

Dari uraian tersebut di atas dapat disimpulkan sebagai berikut:

1. Persendian pergelangan kaki mudah sekali terserang cedera, sendi ini tidak mampu melawan kekuatan medial, lateral, penekanan, dan rotasi. Kesemuanya ini terjadi karena lemahnya otot atau lapisan lemak.

2. Cedera sprain tingkat II pada pergelangan kaki biasanya terjadi robekan pada ligamentum anterior talofibular dan pada ligamentum calcaneofibular yang berakibat ketidakstabilan terus menerus sehingga menjadikan perkembangan yang tidak normal.

3. Upaya untuk mengatasi agar cedera sprain tingkat II tidak bertambah parah dan bahkan segera dapat sembuh adalah dengan cara pemberian pengelolaan cedera tersebut melalui beberapa fase. Setiap fase memiliki tujuan, strategi perawatan dan latihan rehabilitasi yang berbeda-beda untuk menuju ke arah kesembuhan.

4. Keberhasilan dalam pengelolaan cedera sehingga cepat sembuh adalah bergantung pada tingkat kedisiplinan, ketekunan, dan kemauan untuk menjalani semua urutan fase perawatan dan latihan rehabilitasi.

\section{DAFTAR PUSTAKA}

Arnheim, D.D. (1985). Modern Principles of Atbletic Training. United State of America: Times Mirror/Mosby College Publishing.

Brukner, P. dan Khan, K. (1993). Clinical Sports Medicine. Australia: Mc.Graw-Hill Book Company.

Ellison, dkk. (1986). Athletic Training and Sports Medicine. Illinois: The Academy of Orthopaedic Surgeon.

Peterson, L. dan Renstrom, P. (1990). Sports Injuries: Their Prevention and Treatment. London: CIBA-GEIGY.

Sadoso, S. (t.t.). Cedera Olahraga di Arena. (t.k.). 